\title{
Asperity along the North Anatolian Fault imaged by magnetotellurics at Düzce, Turkey
}

\author{
Tulay Kaya ${ }^{1}$, S. Bülent Tank ${ }^{1}$, M. Kemal Tunçer ${ }^{1}$, I. Igor Rokoityansky ${ }^{2}$, Elif Tolak ${ }^{1}$, and Timur Savchenko \\ ${ }^{1}$ Bogazici University, Kandilli Observatory and Earthquake Research Institute, Turkey \\ ${ }^{2}$ National Academy of Sciences of Ukraine, Ukraine
}

(Received April 29, 2008; Revised December 29, 2008; Accepted April 8, 2009; Online published August 31, 2009)

\begin{abstract}
The magnetotelluric (MT) method has been applied to show resistivity variations in the vicinity of the epicenter of the 1999 Düzce earthquake $\left(M_{\mathrm{w}}=7.2\right)$ where a large rupture velocity difference was seen between the western and eastern parts of the epicenter. MT data for frequencies ranging between 320 and $0.0005 \mathrm{~Hz}$ were acquired along two parallel profiles to the west and the east of Düzce earthquake's epicenter. Both profiles crossed the Düzce basin and the Düzce fault in the north and the North Anatolian Fault (NAF) in the south. MT data analysis shows almost two-dimensionality in the region, at the depth starting from 2-3 km beneath the surface. According to two-dimensional MT modeling, a higher resistive layer extends beneath the eastern side of Düzce earthquake epicenter, compared with the western side. This resistivity structure correlates well with the aftershock distribution of the Düzce earthquake.
\end{abstract}

Key words: Turkey, Düzce earthquake, magnetotelluric, resistivity, conductor, rupture velocity.

\section{Introduction}

The highly active North and East Anatolian Faults have contributed to the occurrences of some of the most destructive earthquakes in Turkey. One of these devastating earthquakes, Düzce earthquake, took place in 1999 on the Düzce fault, at the western part of the North Anatolian Fault (NAF) in northwestern Turkey, as shown in Fig. 1. Since the occurence of this devastating earthquake $\left(M_{\mathrm{w}}=7.2\right)$, its parameters and the fault have been investigated using seismological and geodetic data (Ayhan et al., 2001; Bouchon et al., 2001; Akyüz et al., 2002; Bürgmann et al., 2002; Çakır et al., 2003; Birgören et al., 2004; Bouin et al., 2004). Some results of these studies are interesting; for example, the Düzce fault rupture had a dip to the north (Ayhan et al., 2001; Bürgmann et al., 2002; Bouin et al., 2004). Birgören et al. (2004) showed two asperity zones in the region-a large one observed near the hypocenter and a smaller one at the shallow part of the eastern side of the epicenter. Electrically resistive zones were also been seen in the west of the İzmit earthquake (1999) rupture zone, and these were interpreted as indicators of asperity zones (Honkura et al., 2000; Tank et al., 2003, 2005). Seismological studies for the Düzce earthquake also revealed that, during the earthquake, the rupture velocity on the eastern side of the earthquake's epicenter was much greater than that on the western side (Bouchon et al., 2001; Birgören et al., 2004; Bouin et al., 2004; Bouchon and Karabulut, 2008).

The magnetotelluric (MT) method has been shown to be capable of identifying the electrical resistivity structure of the crust and the mantle and has been used for many

Copyright (c) The Society of Geomagnetism and Earth, Planetary and Space Sciences (SGEPSS); The Seismological Society of Japan; The Volcanological Society of Japan; The Geodetic Society of Japan; The Japanese Society for Planetary Sciences; TERRAPUB geophysical studies such as geothermal systems (Çăglar and İşseven, 2004), active volcanoes (Ogawa et al., 1998; Aizawa et al., 2005), petroleum exploration (Constable et al., 1998), crustal structures (Wei et al., 2001; Wannamaker and Doerner, 2002; Gürer, 2004), marine studies (Key and Constable, 2002), mantle properties (Jones, 1999; Simpson, 2002), and active faults (Honkura et al., 2000; Unsworth et al., 2000; Ritter et al., 2005; Tank et al., 2005).

In this study, the MT method was applied to image the Düzce fault's electrical resistivity structure, in the Izmit earthquake region, in order to examine resistivity contrast between the western side and the eastern side of the epicenter. The region in which the Düzce fault lies varies structurally not only from the east to the west but also from the north to the south due to the presence of three different tectonic zones in the vicinity of Düzce. These tectonic zones, the İstanbul-Zonguldak zone, Armutlu-Almacik zone, and Sakarya continent from the north to the south (Fig. 5), play an important role in determining the tectonic structure of Turkey (Yılmaz et al., 1997; Yiğitbaş et al., 1999). A second aim was to image the electrical resistivity variation in these zones; for this we obtained MT data on both sides of the epicenter along two profiles crossing the Düzce basin, the Düzce fault, and the NAF from north to the south, as also shown in Fig. 1(c).

\section{Observation}

MT data in Düzce were obtained in two campaigns. Figure 1(b) shows not only MT sites set up after the Düzce earthquake but also those in the region after the 1999 İzmit earthquake. The first MT profile (DW) across the Düzce fault was extended from Çilimli in the north to Taşkesti village in the south, an almost $36-\mathrm{km}$-long profile with station spacing varying from $1.3 \mathrm{~km}$ to $5.7 \mathrm{~km}$. At each station, two 


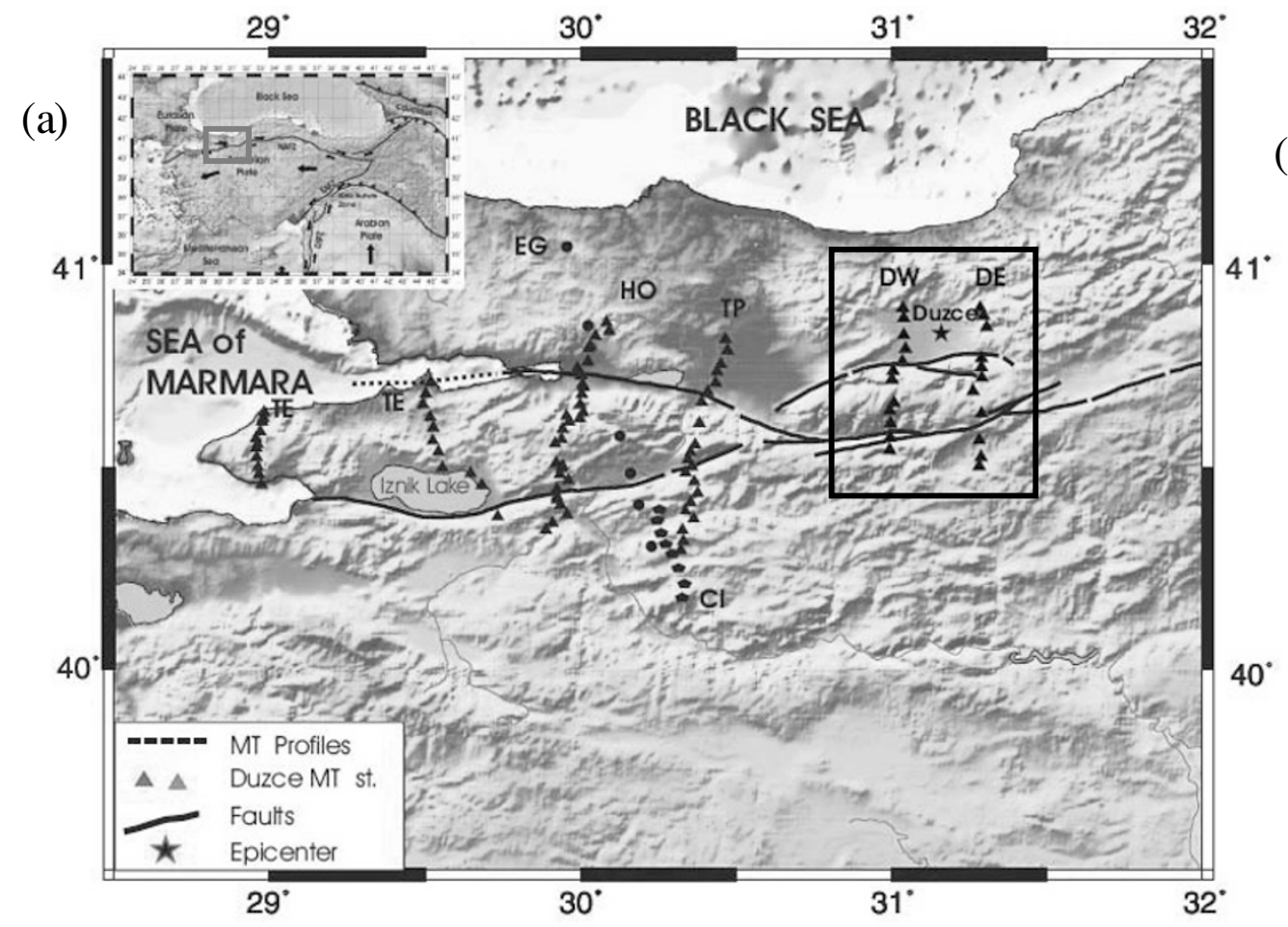

(b)

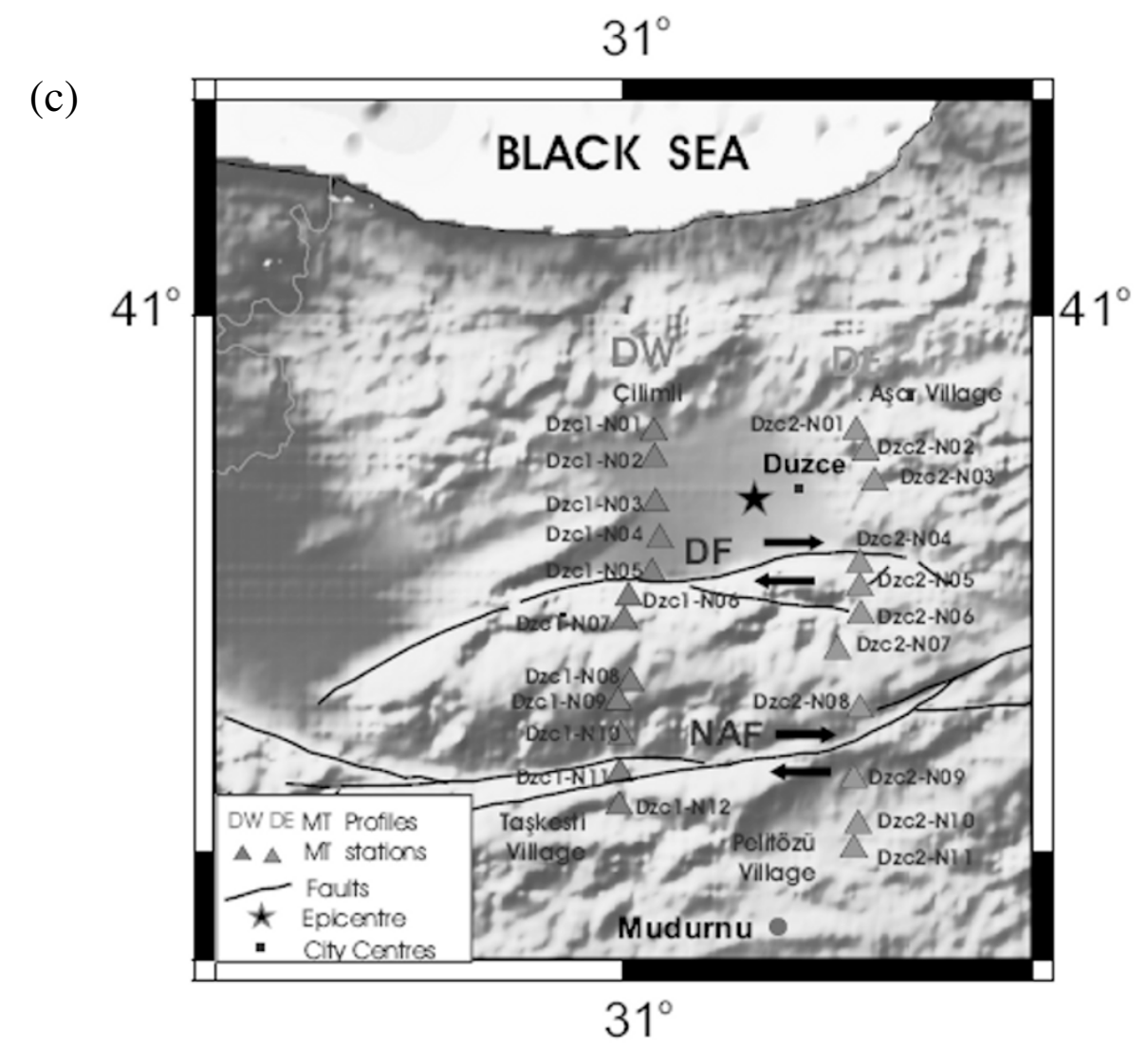

Fig. 1. (a) The tectonic map of Turkey indicating the study area with an open red square. (b) Location map of the previous magnetotelluric measurement profiles in the vicinity of Düzce region. The lines indicate the studied area as follows: HO by Honkura et al. (2000) and Oshiman et al. (2002), TE by Tank et al. (2003), EG by Elmas and Gürer (2004), CI by Çağlar and İsseven (2004) and TP by Tank et al. (2005). (c) The map of Düzce region showing the locations of the west (DW) and east (DE) profiles together with tectonics in this area. Black lines and black arrows represent the fault lines and relative motions of the faults, respectively. Red and blue triangles with numbers represent MT stations of the west and east profiles. The star indicates the epicenter of 1999 Düzce earthquake (from USGS). 
a-1
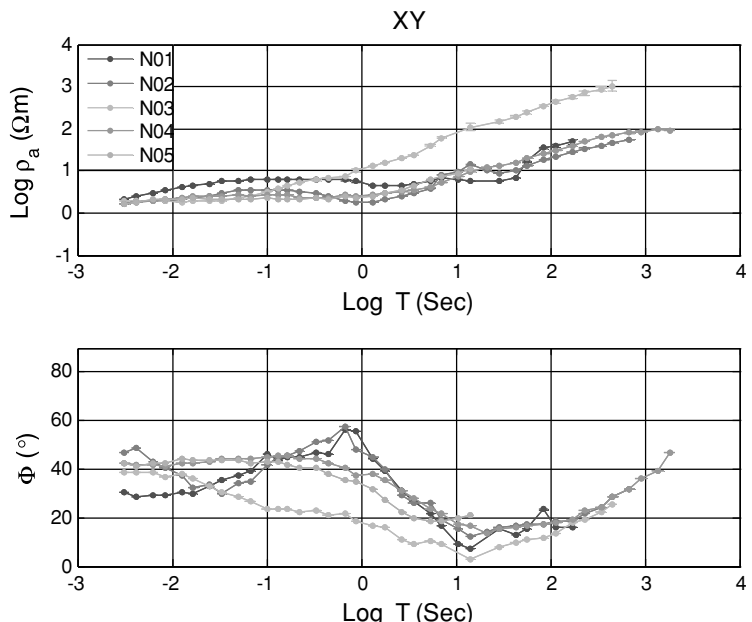

a-2
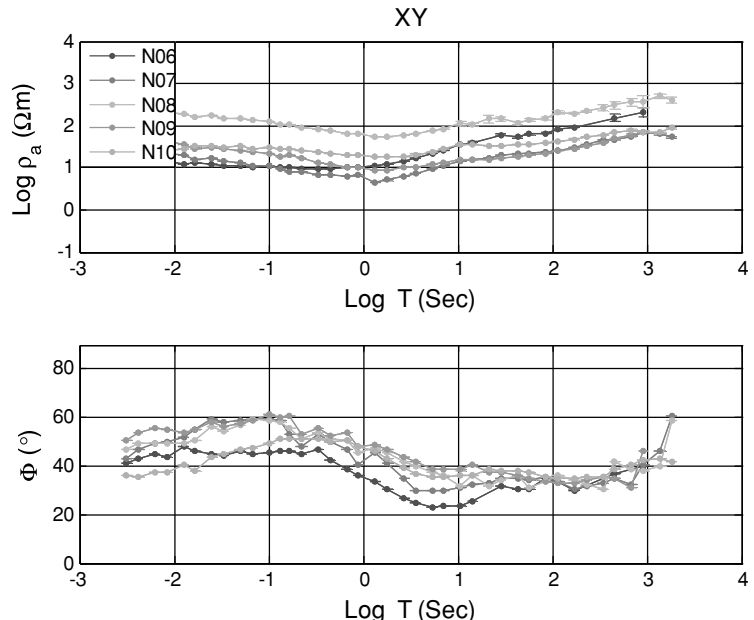

a-3
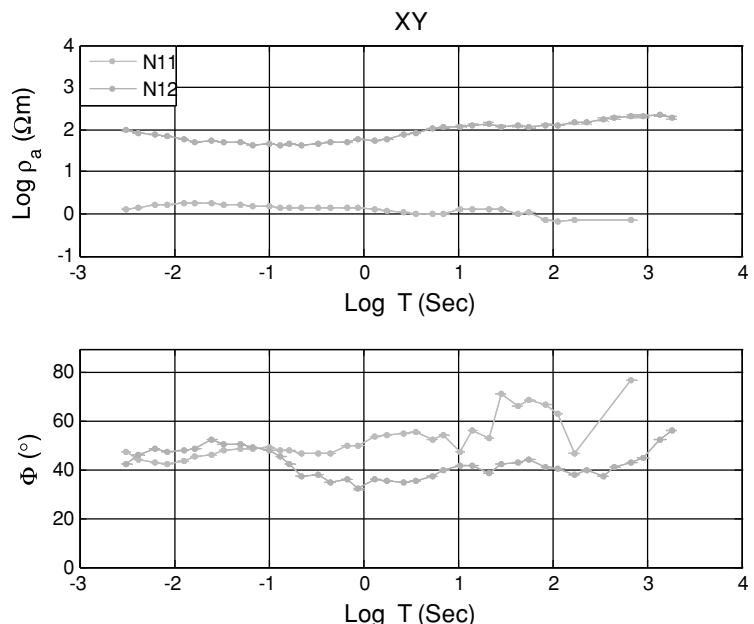

b-1
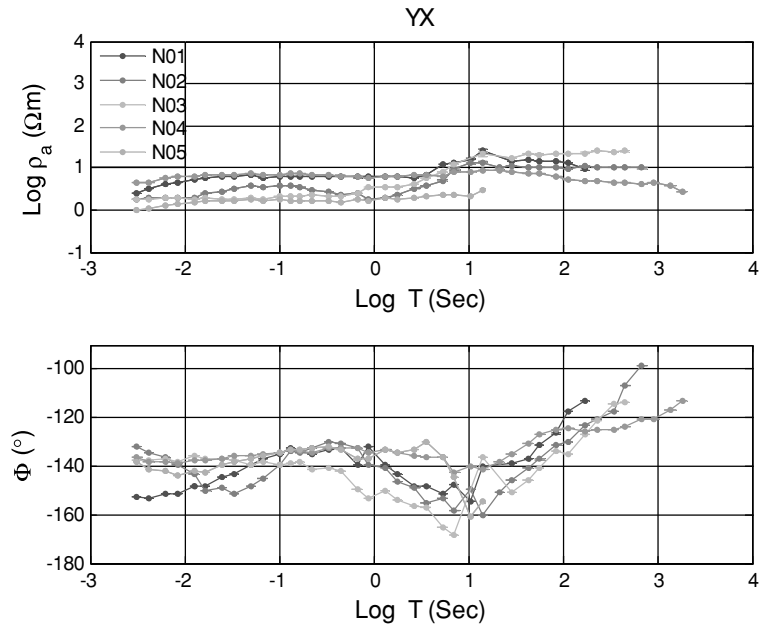

b-2
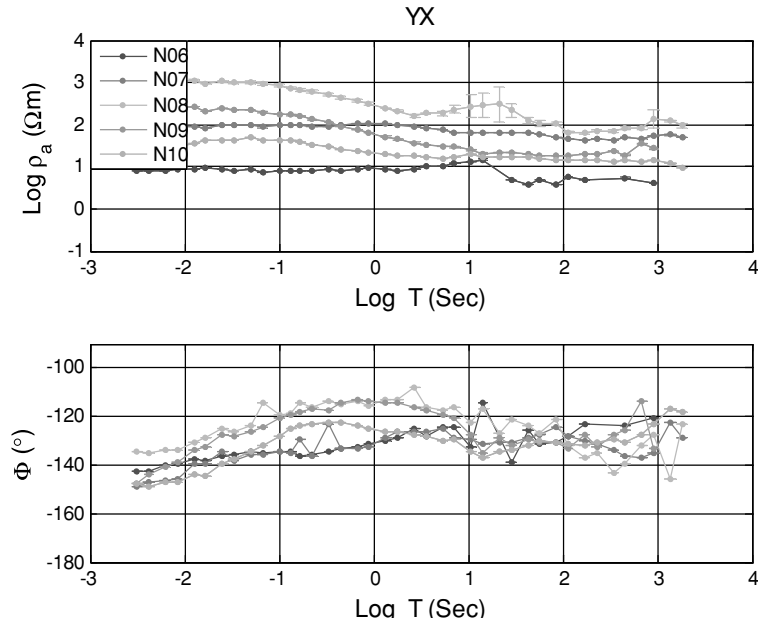

b-3
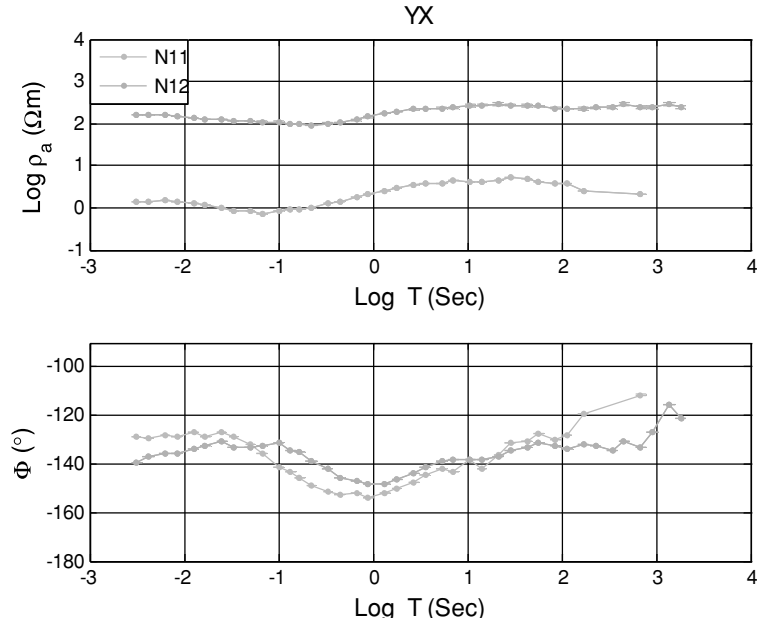

Fig. 2. Apparent resistivity and phase curves of the XY (a, c) and YX (b, d) modes for DW (a, b) and DE (c, d) profiles. Increase in the resistivity values to the south, from Düzce basin to the highland, is clearly seen on both modes. 
C-1
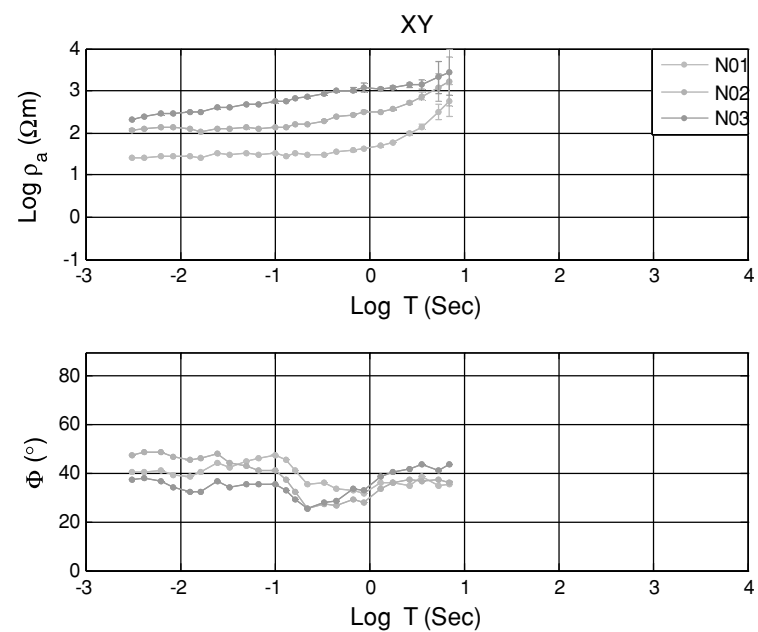

c-2
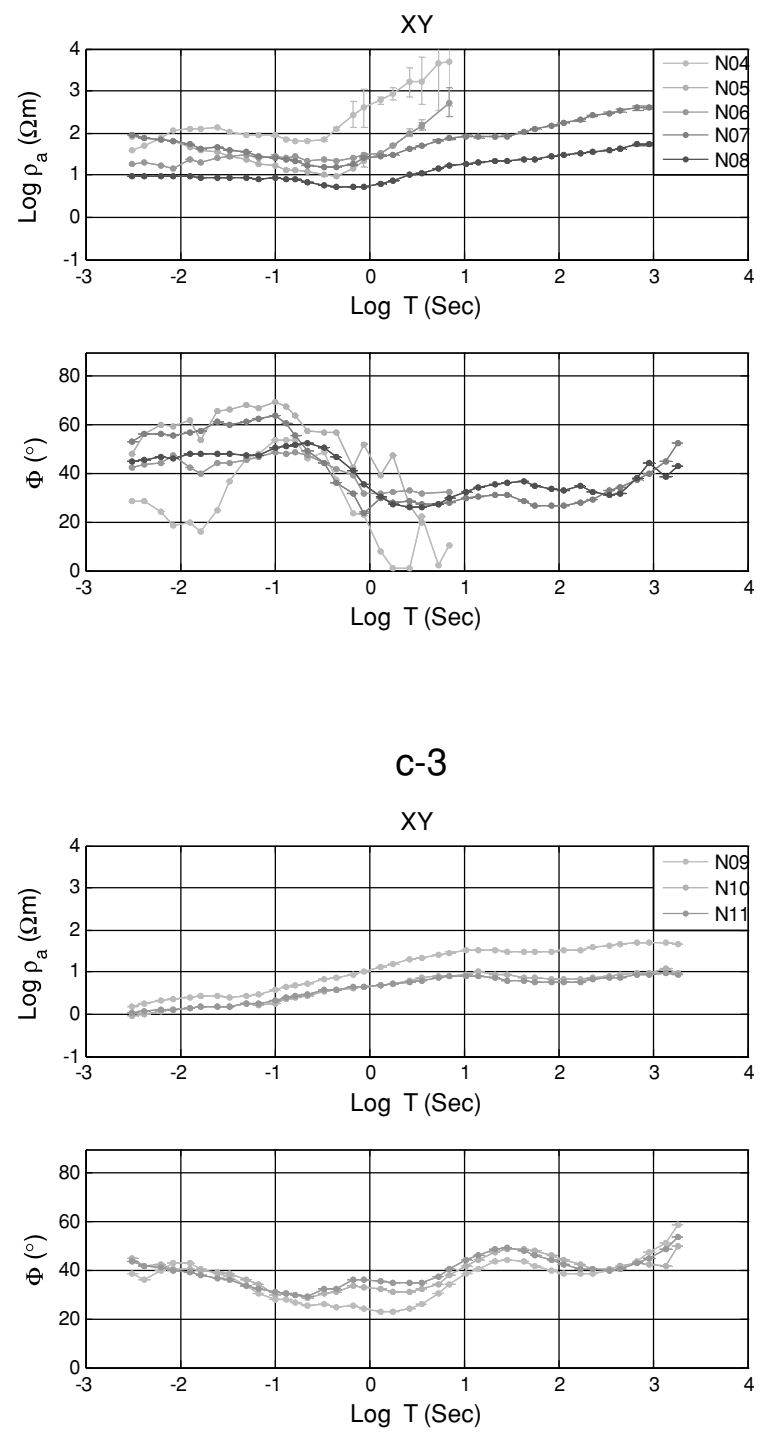

d-1
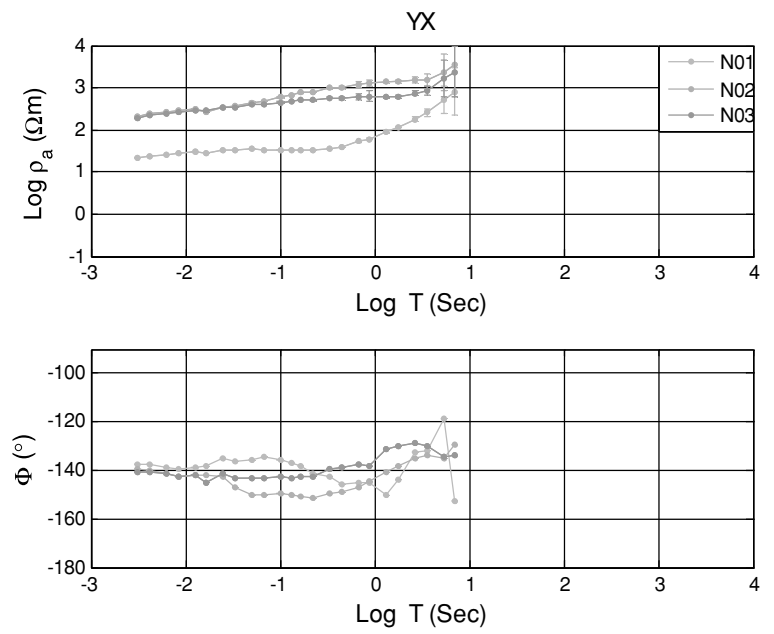

d-2
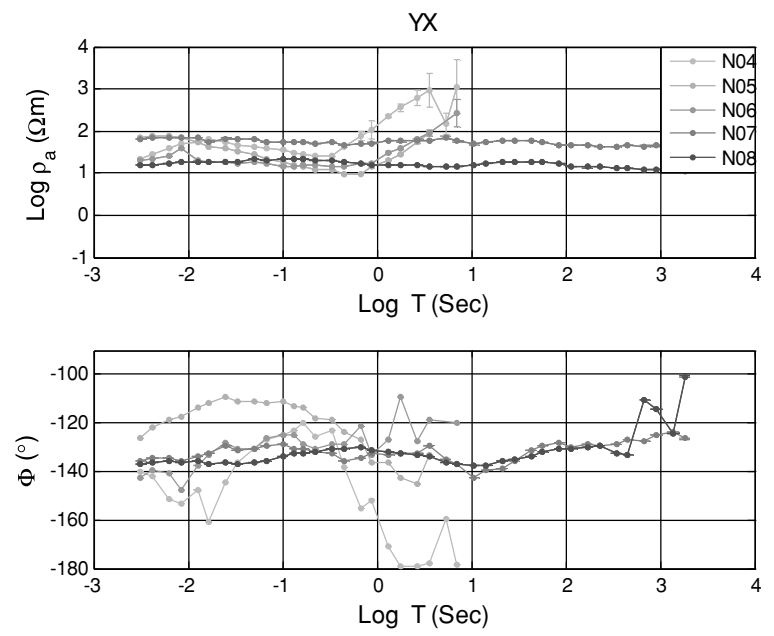

d-3
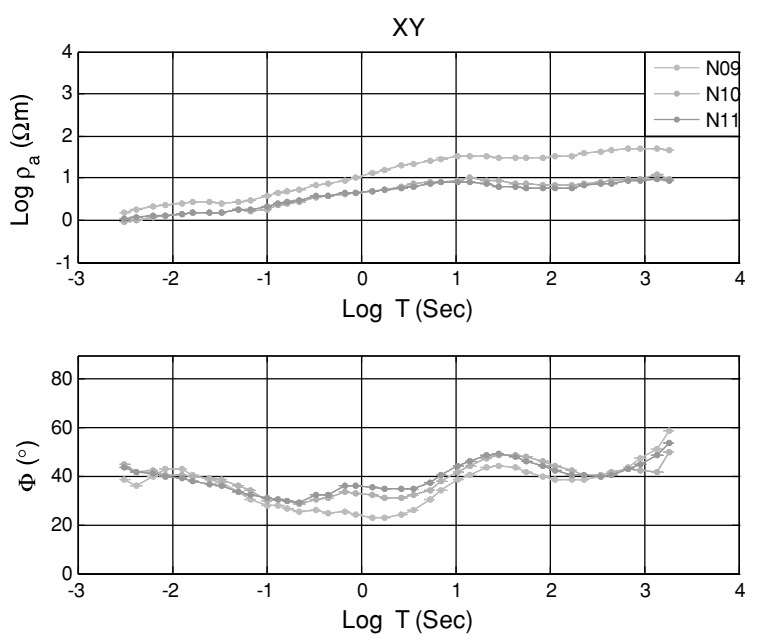

Fig. 2. (continued). 

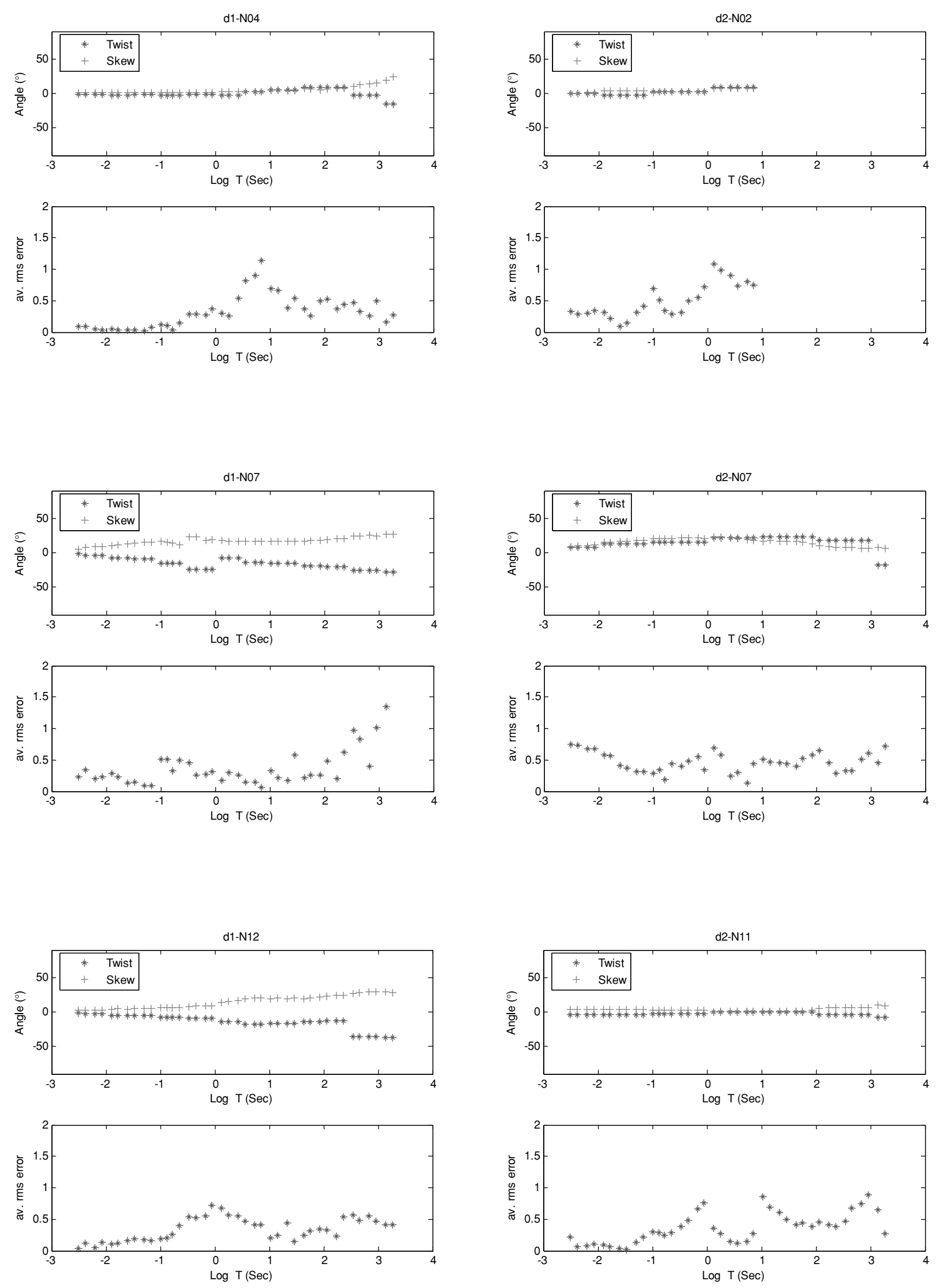

(a)

(b)

Fig. 3. Twist and skew angles and average rms errors versus period for the three sample stations of the DW (a) and DE (b) profiles. 


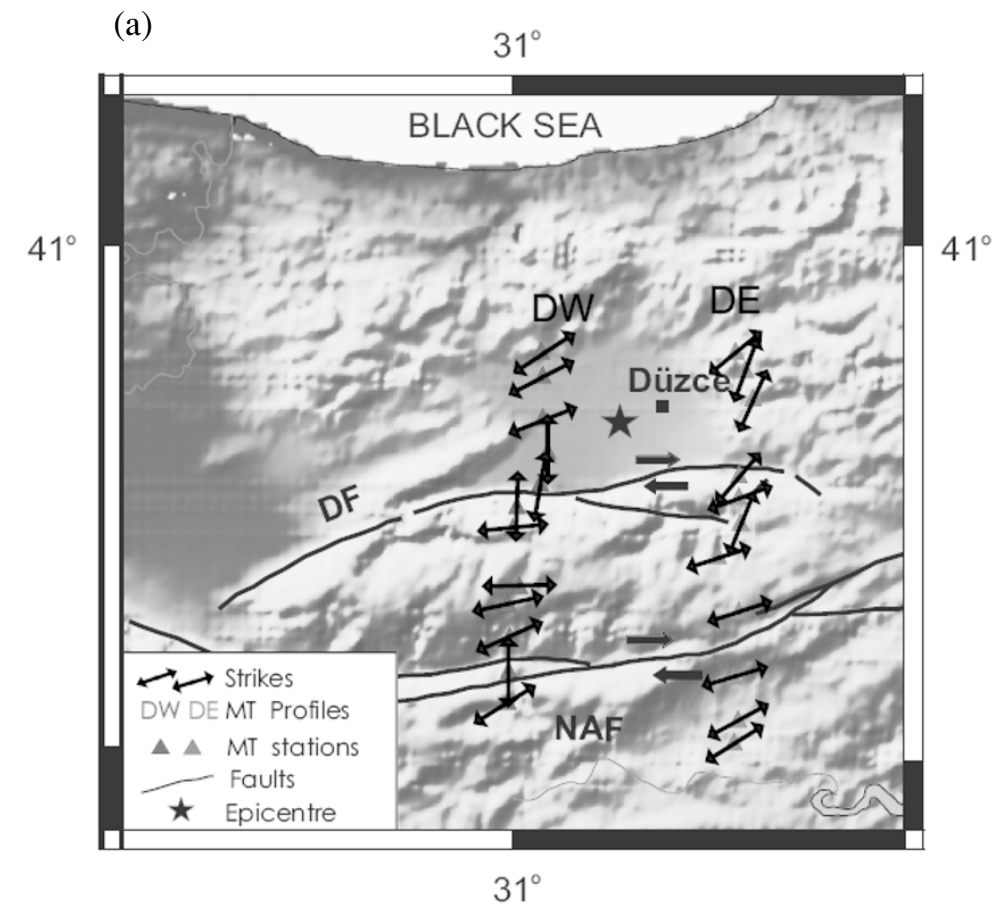

(b)

\begin{tabular}{|c|c|c|}
\hline DW & F (Hz.) & $\mathrm{DE}$ \\
\hline$=\frac{n}{x}$ & $1000-100$ & \\
\hline$=\frac{k^{\prime}}{k}$ & $100-10$ & \\
\hline & $10-1$ & \\
\hline & $1-0.1$ & \\
\hline & $0.1-0.01$ & \\
\hline & $0.01-0.001$ & \\
\hline & $0.001-0.0001$ & \\
\hline
\end{tabular}

(c)

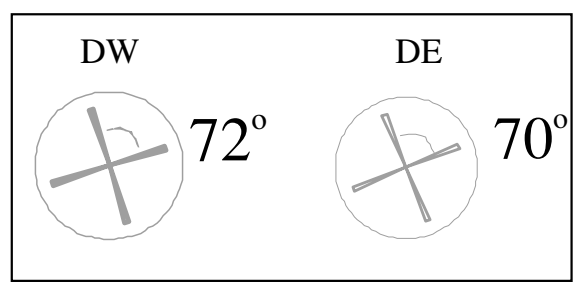

Fig. 4. (a) The geo-electric strike at each station for the whole frequency band. Pink and blue arrows indicate the strikes for the DW and DE profiles, respectively. (b) Geo-electric strikes of the DW and DE profiles for each frequency band. (c) Geo-electric strikes for the whole frequency band for the DW and DE profiles.

electric and three magnetic components were recorded for the frequency range between 320 and $0.0005 \mathrm{~Hz}(\sim 1820 \mathrm{~s})$ by three Phoenix Geophysics MTU-5A instruments operated synchronously during 16-18 h. Remote reference processing (Gamble et al., 1979) was used at noisy stations. Magnetic coils for horizontal magnetic components and electric dipoles $\sim 60 \mathrm{~m}$ long were oriented along the geomagnetic north and east. The Düzce fault strike is $\mathrm{N} 85^{\circ} \mathrm{E}$ (Bürgmann et al., 2002; Bouin et al., 2004), and thus the orientation of the profile $(\mathrm{N}-\mathrm{S})$ is almost perpendicular to the Düzce fault, as shown in Fig. 1.

The east profile (DE) was located almost $23 \mathrm{~km}$ to the east of DW profile. It is about $41 \mathrm{~km}$ long, extending from Aşar village in the north to the Pelitözü village (Mudurnu) in the south. It is composed of 11 stations with a site separation ranging from 2 to $7 \mathrm{~km}$. During the second campaign, data were acquired at seven stations. Along the DE profile, the data were recorded for the same frequency range as that along the DW profile.

\section{Data Analysis}

As a first step in the processing, the data transformed from the time domain to the frequency domain were plotted as apparent resistivity and phase curves versus period. 
(a)

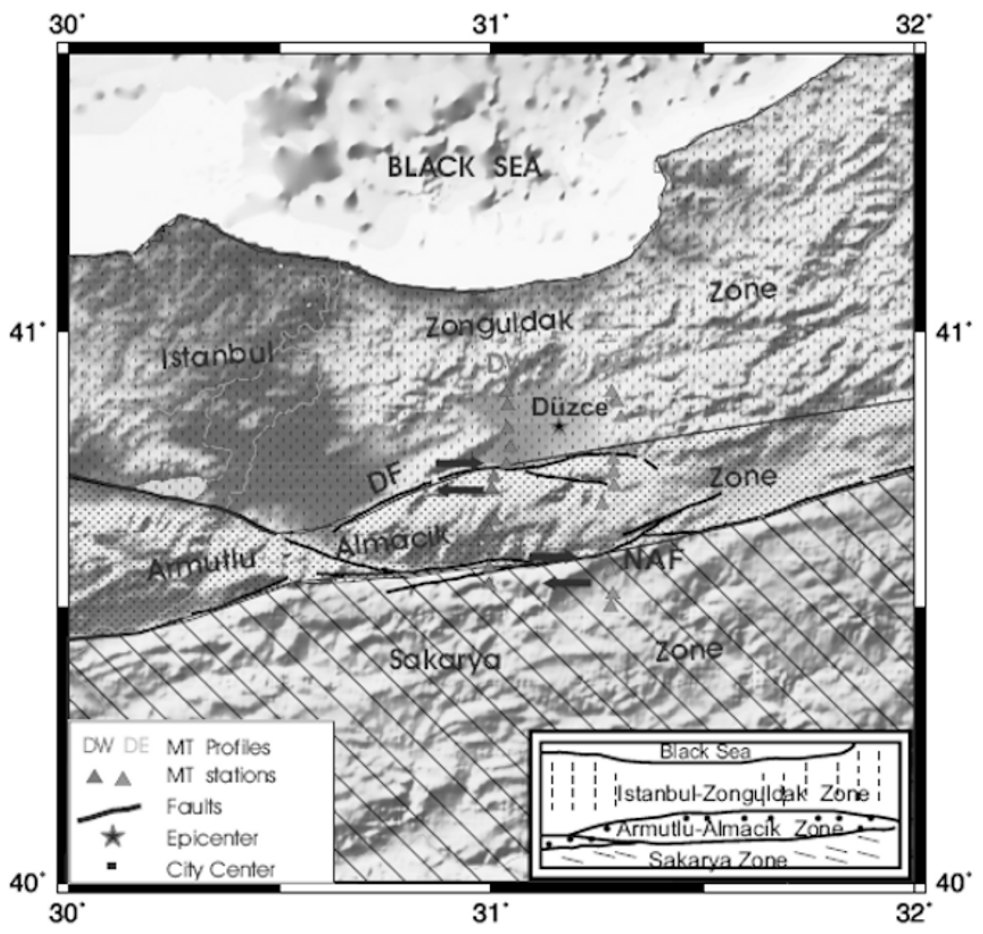

(b)

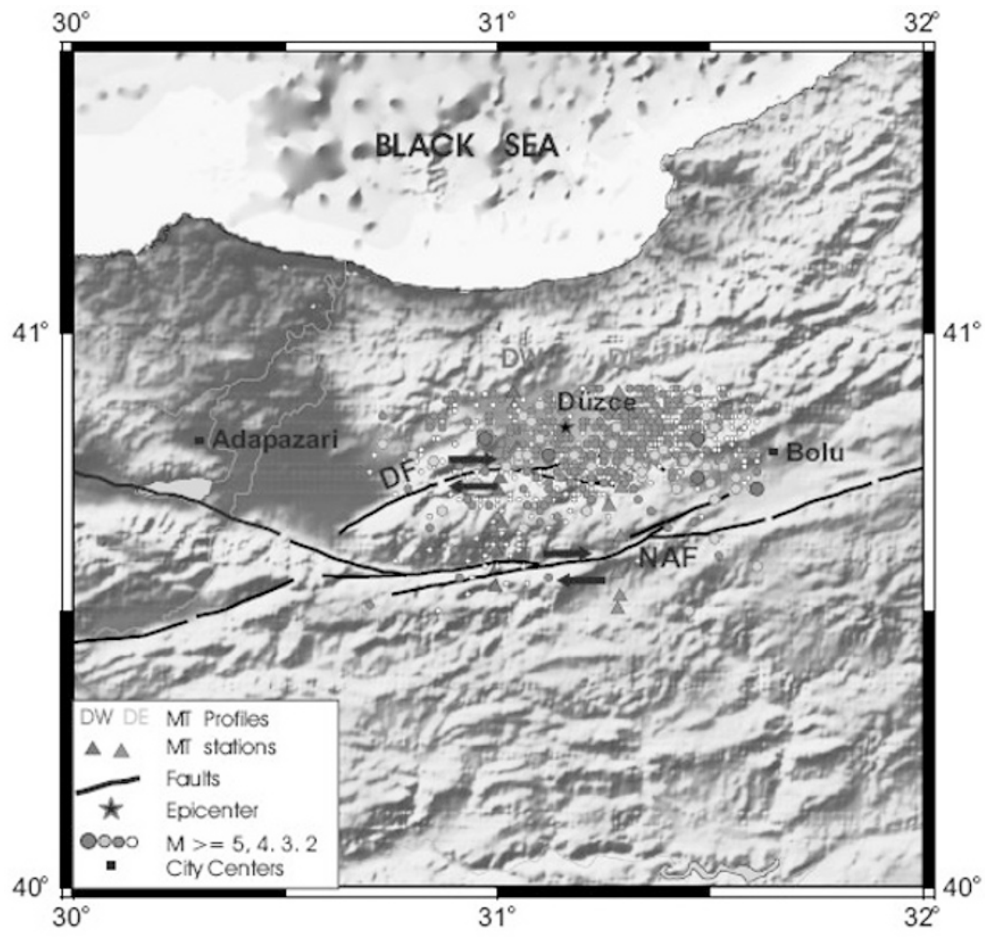

Fig. 5. (a) Tectonic map of the Düzce region (Yllmaz et al., 1997). Black lines show active faults in the region. The black arrows indicate the direction of fault motion. The star indicates the epicenter of the Düzce earthquake. (b) Map of aftershock distribution of the Düzce earthquake. Red, pink, and purple circles are the aftershocks having magnitudes $M \geq 5, M \geq 4$, and $M \geq 3$, respectively (observed for 3 month after the main shock, B. U., Kandilli Observatory and Earthquake Research Institute).

The whole data set was investigated separately, and general information about the resistivity feature of the region was obtained. According to this analysis, the apparent resistivity curves could be classified into three groups from the north to the south. In Fig. 2, apparent resistivity curves demonstrate a resistivity transition from low at the basins (Düzce and Mudurnu) to high at higher altitudes (Almacık Mountain) for both the west (Fig. 2(a, b)) and east (Fig. 2(c, d)) profiles.

Effects of galvanic distortions produced by near-surface 
(a)

Observed
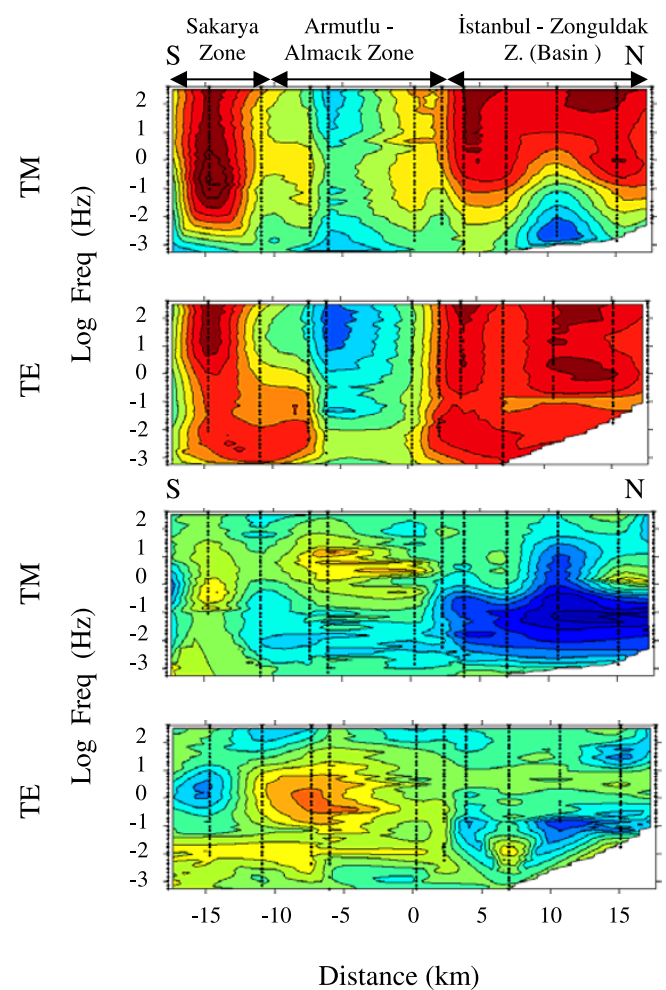

(b)

\section{Calculated}
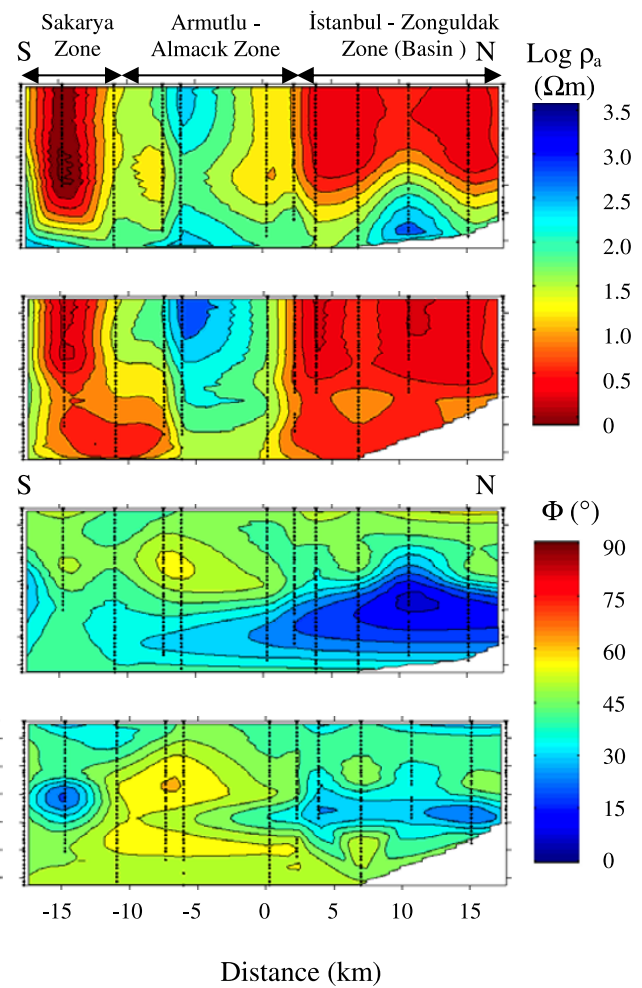

Fig. 6. Observed and calculated apparent resistivity and phase pseudosections for the DW profile. (a) Observed apparent resistivity (upper two) and phase (bottom two) pseudosections of TM and TE modes, respectively, from the top to the bottom. (b) Calculated apparent resistivity and phase pseudosections in the same notation as (a). In pseudosections, high resistivity is indicated in blue whereas low resistivity in red.
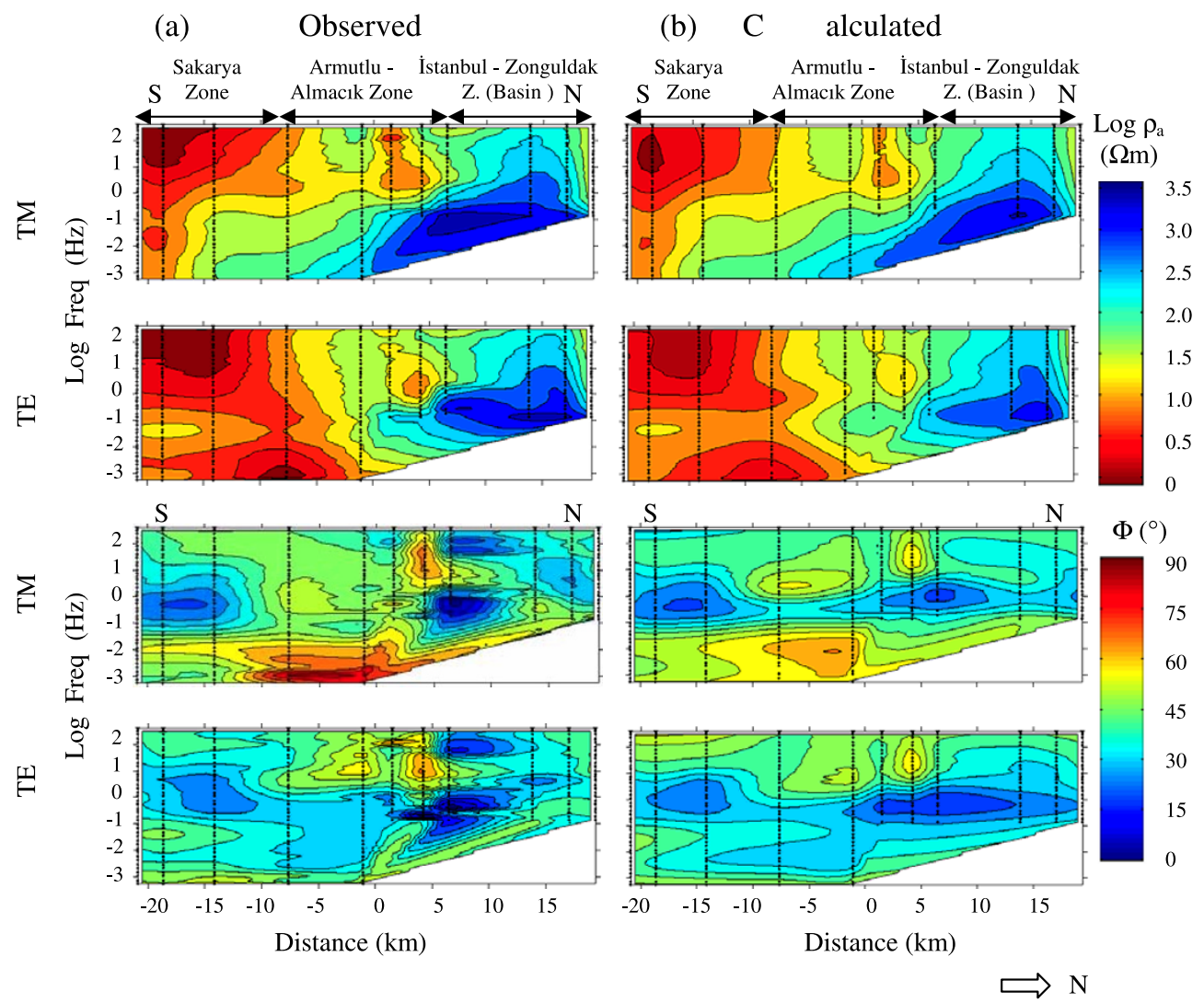

Fig. 7. Observed and calculated apparent resistivity and phase pseudosections for the DE profile. (a) Observed apparent resistivity (upper two) and phase (bottom two) pseudosections of TM and TE modes, respectively. (b) Calculated apparent resistivity and phase pseudosections in the same notation as in (a). In pseudosections, high resistivity is indicated in blue whereas low resistivity in red. 
inhomogeneities can be estimated from MT data by a tensor decomposition technique, namely the Groom-Bailey (GB) decomposition (Groom and Bailey, 1989). The twist $\left(-25^{\circ}\right.$ and $\left.25^{\circ}\right)$ and skew $\left(\sim 0^{\circ}\right)$ angles obtained from the decomposition show that our two dimensional (2D) data set is under the effect of moderate telluric distortion. In Fig. 3, the twist and skew values with average errors are shown for three sample stations. The data fit is acceptable over the whole sites, and these small root mean square (rms) misfit values indicate the accuracy of the $3 \mathrm{D} / 2 \mathrm{D}$ galvanic distortion model. Applying the GB decomposition, the strike angle was determined and, subsequently, geo-electric strike values at every station for every frequency were calculated. After that, McNeice and Jones' (2001) approach, which is an extended form of the Groom and Bailey decomposition, was applied to whole stations and periods. In this manner, frequency- and site-dependent geo-electric strike variation for every separate site was obtained together with the frequency- and site-independent strike for profiles (Fig. 4). As seen from Fig. 4(a), most of the geo-electric strikes show an angle near $\mathrm{N} 70^{\circ} \mathrm{E}$. The frequency-dependent strikes estimated for both the profiles are displayed in Fig. 4(b). The frequency- and site-independent strikes obtained by the multisite multifrequency decomposition analysis of $\mathrm{McNe}-$ ice and Jones (2001) are $\mathrm{N} 72^{\circ} \mathrm{E}$ and $\mathrm{N} 70^{\circ} \mathrm{E}$ for the DW and DE profiles, respectively (Fig. 4(c)). These strike values for the undistorted MT data are highly consistent with the geological strike.

\section{2D Modeling}

After the MT data of the DW and DE profiles were decomposed, they were rotated to the geo-electric coordinate frames. Subsequently, the data set was inverted by the 2D inversion code developed by Ogawa and Uchida (1996), which uses the static shift as a constraint and handles the static shift effect during the inversion. Because of the relative sensitivities of the TE (transverse electric) and TM (transverse magnetic) modes (Berdichevsky et al., 1998), both modes were used during inversion process of the decomposed MT data. A uniform Earth model having as resistivity of $100 \Omega \mathrm{m}$ was taken as an initial model. For each of the profiles, many combinations of different values were tried for trade-off parameters, smoothing parameter $\alpha$, and static shift parameter $\beta$. The error floor was taken as $10 \%$ for the apparent resistivity data and $5 \%$ for the phase data. After 15 iterations, the smoothest models $(\sim 2 \mathrm{rms})$ that minimize the misfit between the observed and calculated apparent resistivity and phase values for the DW and DE profiles were obtained.

\section{Discussion}

As shown in Fig. 4(c), the strikes were obtained as $\mathrm{N} 72^{\circ} \mathrm{E}$ and $\mathrm{N} 70^{\circ} \mathrm{E}$ for the DW and DE profiles, respectively. Geodetic and seismological studies give the geological strike within a range between $\mathrm{N} 82^{\circ} \mathrm{E}$ and $\mathrm{N} 95^{\circ} \mathrm{E}$ (Ayhan et al., 2001; Çakır et al., 2003; Bouin et al., 2004). Bürgmann et al. (2002) derived the strike of Düzce fault

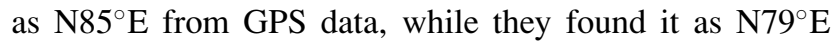
from InSAR data. On the other hand, Tibi et al. (2001) obtained the Düzce fault strike from teleseismic body waves as $\mathrm{N} 75^{\circ} \mathrm{E}$. The geo-electric strike in this study is consistent with these strikes.

The apparent resistivity and phase pseudosections, shown in Figs. 6 and 7, obtained after decomposition denote well the electrical resistivity transition in three tectonic zones. These three zones from the north to the south represent the İstanbul-Zonguldak zone, Armutlu-Almacik zone, and Sakarya continent parts of the western Pontides in the region (Yılmaz et al., 1997; Yiğitbaş et al., 1999). Figures 6 and 7 also include calculated apparent resistivity and phase values obtained as a result of inversion. Comparisons between the observed and calculated apparent resistivity and phase for DW and DE profiles show that apparent resistivity and phase amplitudes are almost well recovered. The correlation of the observed and calculated apparent resistivity and phase values was also observed in fitting curves for both modes of DW and DE profiles, some samples of which are shown in Figs. 8 and 9, respectively.

The electrical resistivity models represented in Figs. 10(a) and 10(b) clearly show the same surface structures to the depth of $\sim 3-4 \mathrm{~km}$ for the DW and DE profiles, except for the Düzce basin. North of the DW profile, the Düzce basin composed of young sediments is observed at a depth of $\sim 3 \mathrm{~km}$ as a surface conductor (C2 in Fig. 10(a)). Şengör et al. (2005) give the thickness of the sedimentary layer as about $260 \mathrm{~m}$ and claim that the Eocene volcanogenic flysch extends beneath the Düzce basin. The continuation of the conductor to the depth of 3-4 km may be interpreted as an effect of Eocene volcanogenic flysch beneath the Düzce basin. A relatively low resistivity zone (R3) is seen at the same depth of the DE profile (Fig. 10(b)) where northern stations are not in the Düzce basin. The resistive layer R2 is most probably related to the Precambrian crystalline basement in the region (Yilmaz et al., 1997). To the south of both the profiles, 2-3-km-thick conductors (1-5 $\Omega \mathrm{m}$ ) exist beneath the Düzce fault, which may be formed as a result of the faulting. Further to the south, another conductor with a low resistivity of $\sim 15-20 \Omega \mathrm{m}$ exists (C3 in Figs. 10(a) and 10 (b)), and it is overlain by a resistive layer of $\sim 500 \Omega \mathrm{m}$ (R1 in Figs. 10(a) and 10(b)), which is composed of late Cretaceous ophiolitic mélange over the highland between the Düzce fault and NAF (Yılmaz et al., 1997; Yiğitbaş et al., 1999). This layer represents the transition of different kinds of metamorphics beneath the Almacik Mountains. A conductive layer (C1) to a depth of $1 \mathrm{~km}$ is present below the NAF trace (Figs. 10(a) and 10(b)) for both the profiles. This conductor is interpreted as corresponding to younger sediments located near the fault zone and Mudurnu Valley.

At deeper parts, the DW and DE electrical resistivity models represent different structures. For DW, from $\sim 7 \mathrm{~km}$, a conductive layer C4 (Fig. 10(a)) deepens to the north. This conductive layer with resistivity of $\sim 20 \Omega \mathrm{m}$ represents the transgressive sedimentary sequence, which was also observed in the north of the Sakarya continent (Y1lmaz et al., 1997). We checked the thickness of this conductive layer as well as its magnitude, applying a sensitivity test. To this end, the resistivity of the conductor was changed to 100 and $500 \Omega \mathrm{m}$, and their responses were obtained separately applying $2 \mathrm{D}$ forward modeling. In both modes we realized 


\section{DW}

(TE)
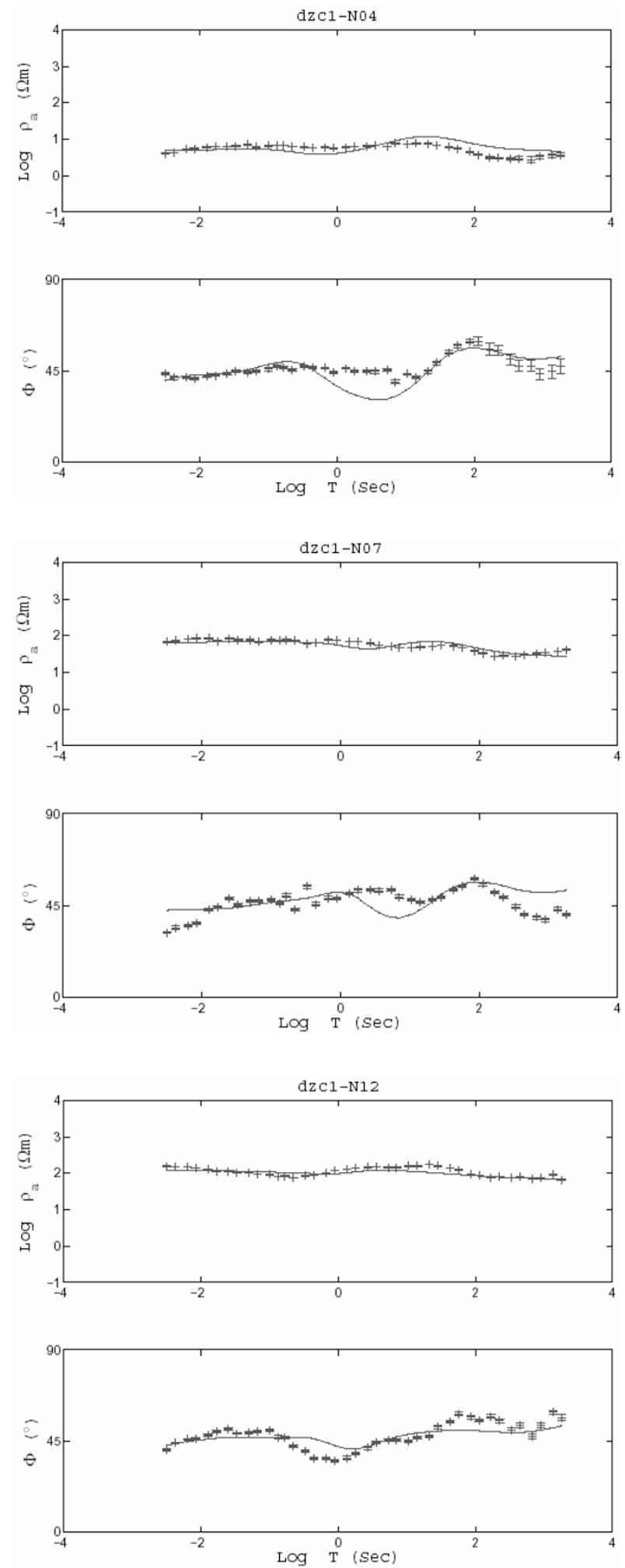
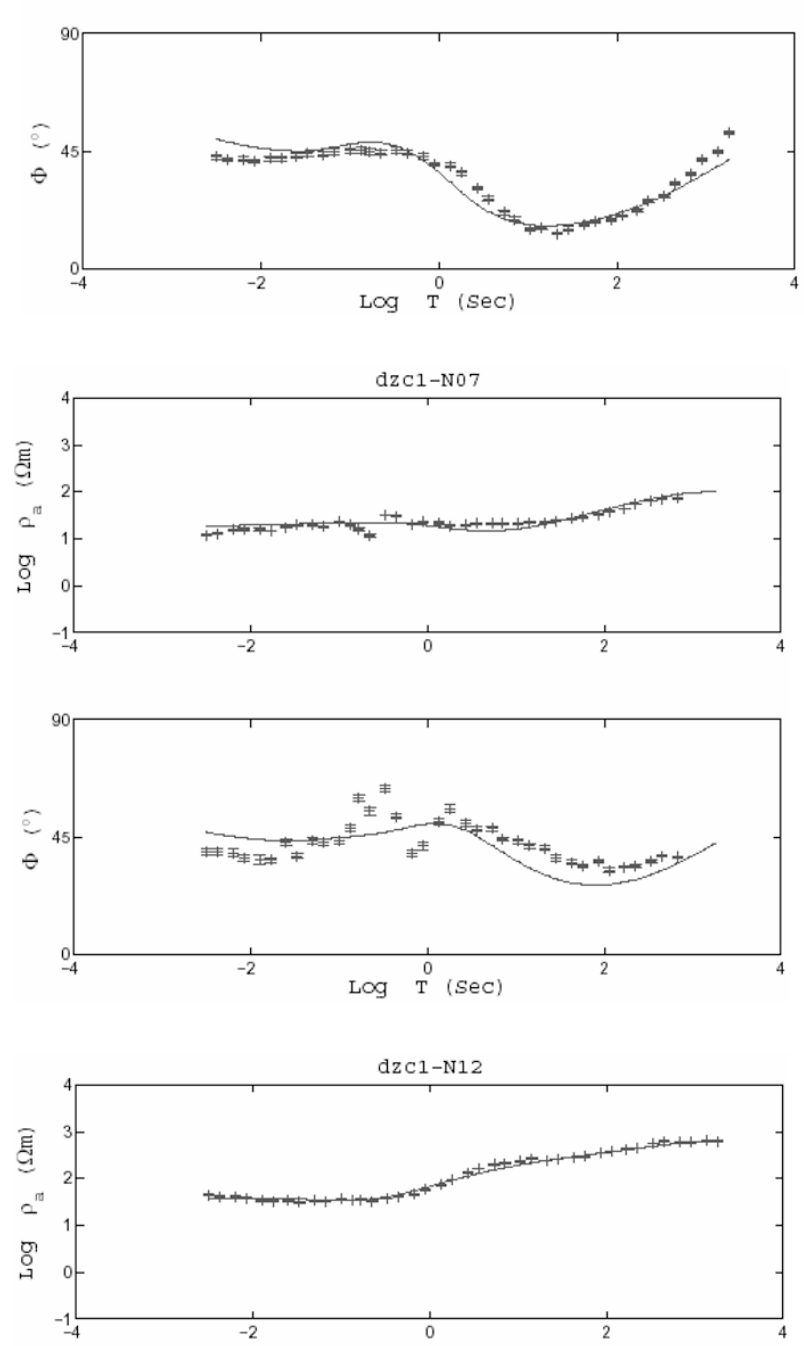

(TM)
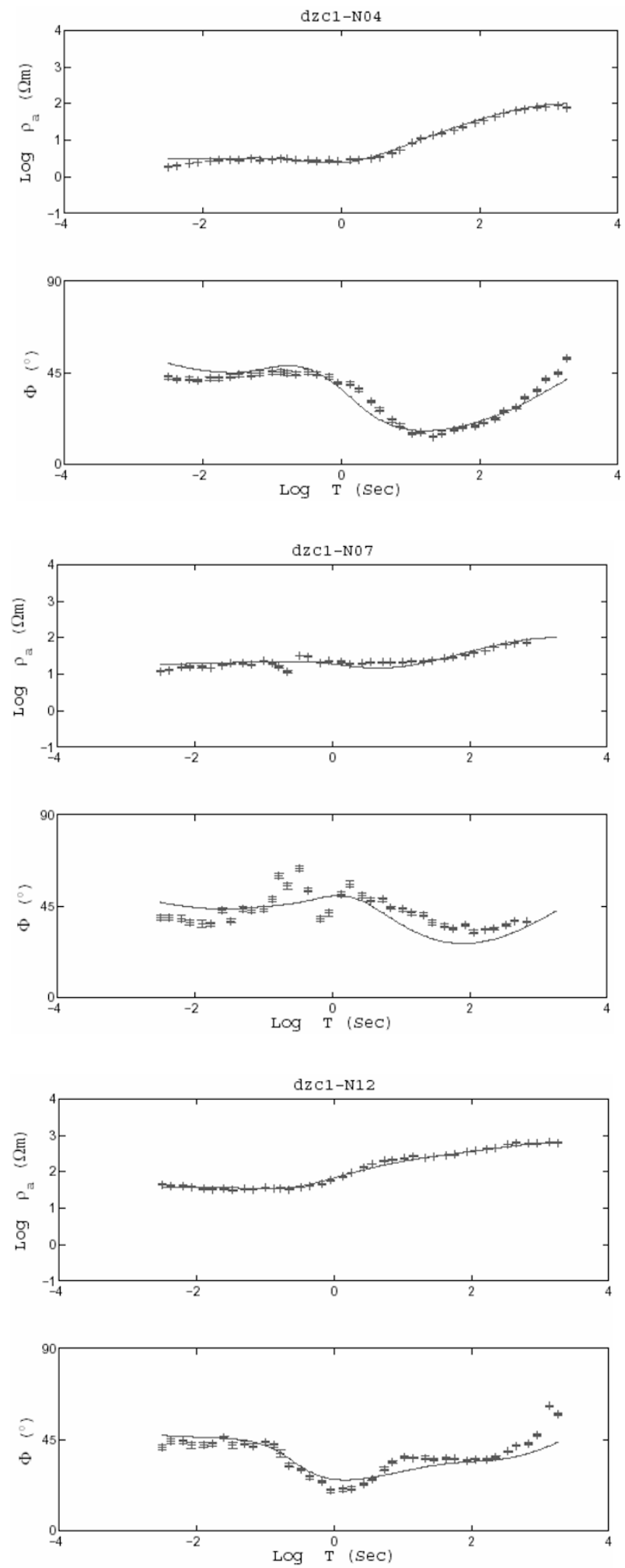

Fig. 8. Sample fitting curves of observed and calculated data obtained from TE (left) and TM (right) mode of the DW profile. Dotted lines with error bars denote the observed data while solid lines represent the model response. 


\section{$\mathrm{DE}$}

TE
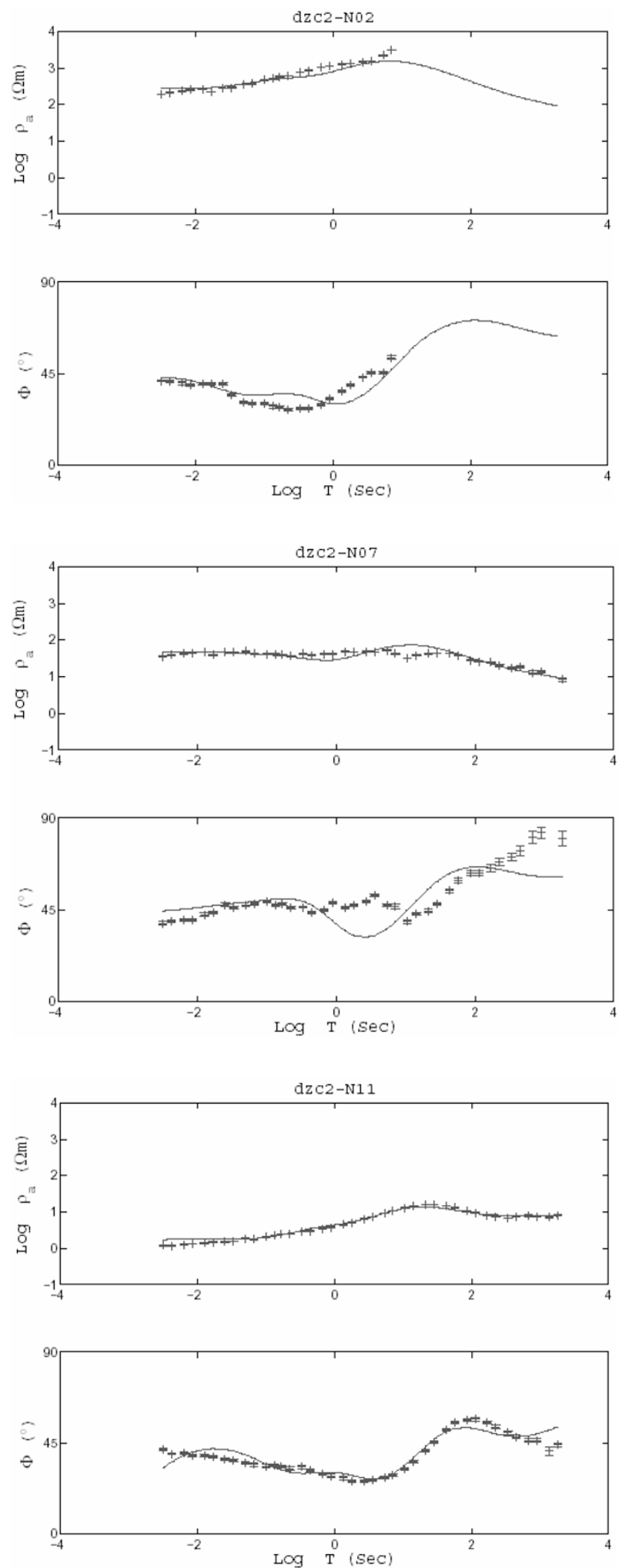

$\mathrm{TM}$
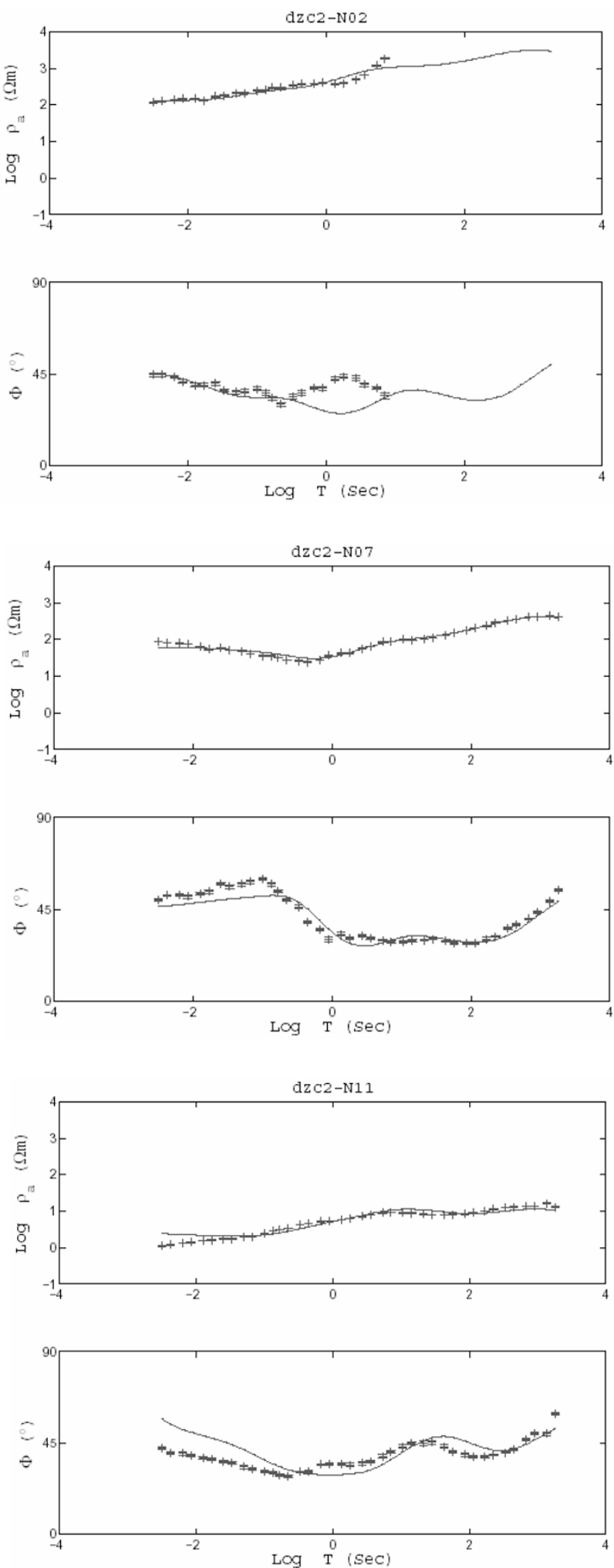

Fig. 9. Sample fitting curves of observed and calculated data obtained from TE (left) and TM (right) mode of the DE profile. Dotted lines with error bars denote the observed data while solid lines represent the model response. 


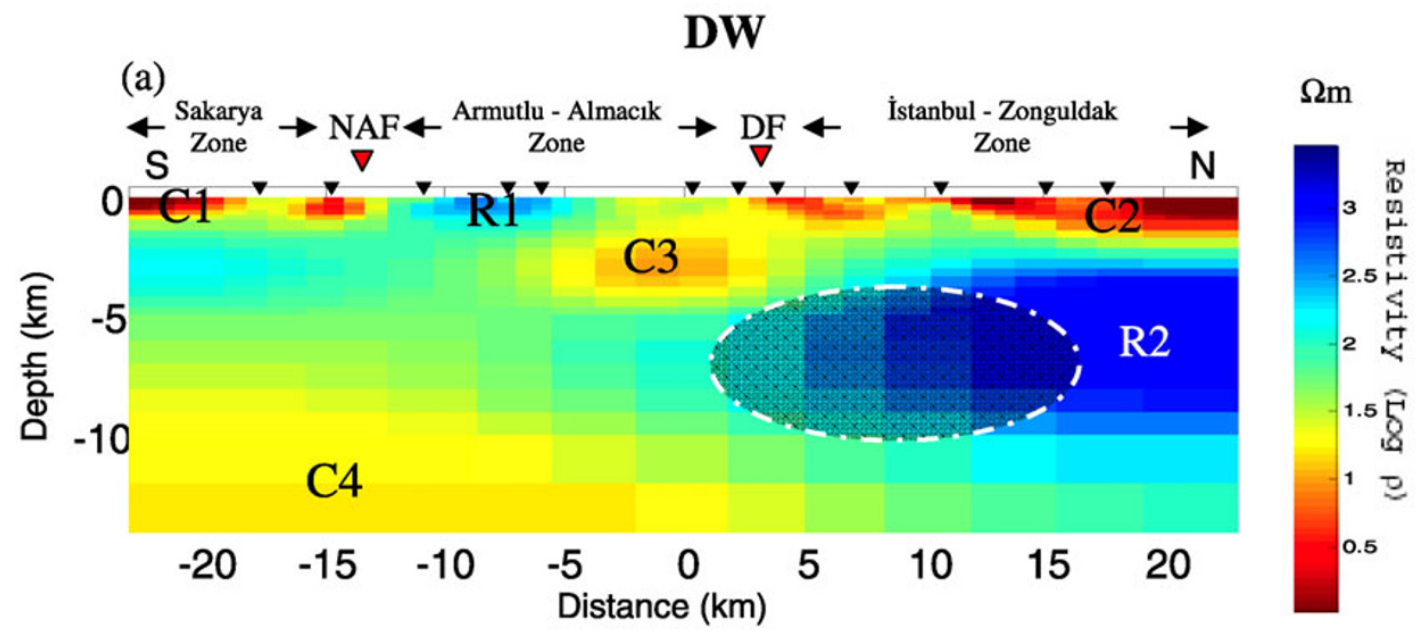

(b)

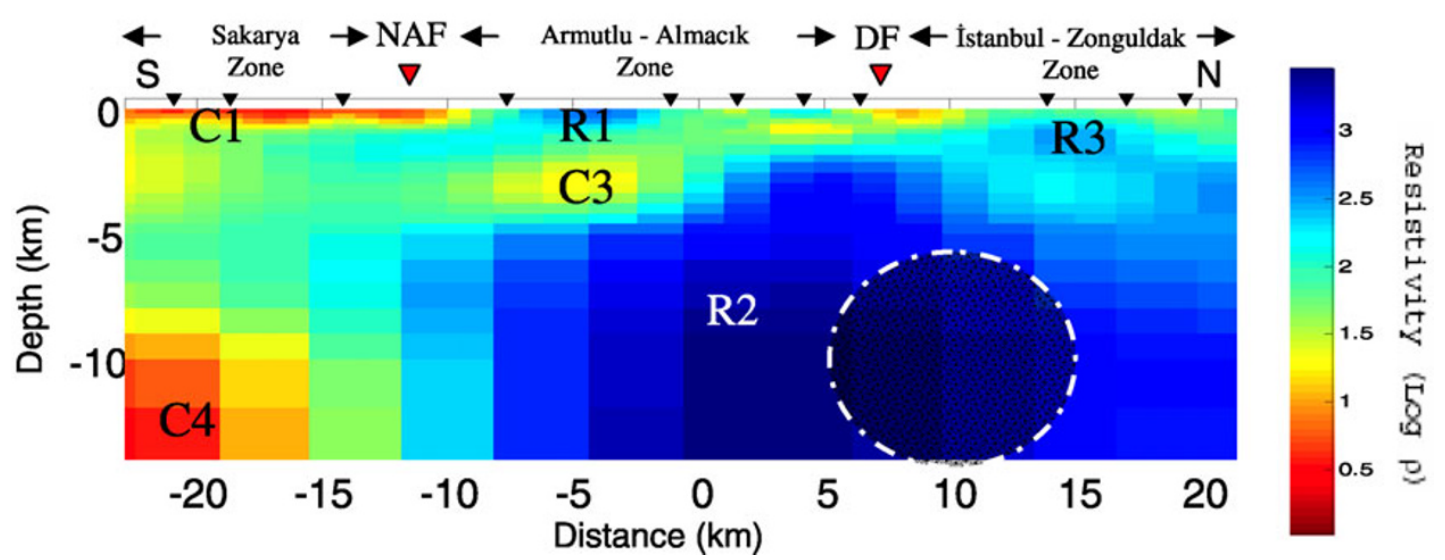

Fig. 10. Final resistivity models for (a) DW and (b) DE profiles obtained from joint inversion of the TE and TM mode data. Black triangles at the surface represent MT stations. Red triangles indicate NAF and the Düzce fault from the south to the north, respectively. Color variation in models from red to blue denotes the increase in the resistivity. Circles including sparse and dense dots show the aftershock areas and represent sparse and dense aftershocks beneath the western and the eastern sides of the epicenter, respectively.

that the conductor beneath the south station is necessary. The thickness of the conductor was tested by bounding the extension depth of the conductor to 12 and $20 \mathrm{~km}$ and also changing the resistivity of the conductor to $500 \Omega \mathrm{m}$ beneath this depth. We observed that the conductor extends to a depth greater than $20 \mathrm{~km}$, and that the resistive basement does not fit the observed data, implying that a low resistive layer is required at this location. At a depth from $\sim 4$ to $\sim 10 \mathrm{~km}$, a resistive layer (R2 in Fig. 10(a)) with a resistivity of a few hundred $\Omega \mathrm{m}$ extends from the center to the northern edge of the DW profile, and its resistivity gets lower as the depth increases. A smaller conductive layer (C4 in Fig. 10(b)) also exists at the southern edge of the DE profile, having the resistivity lower than the conductive layer (C4 in Fig. 10(a)) at the south end of the DW profile. A very high resistivity zone with a few thousand $\Omega \mathrm{m}(\mathrm{R} 2$ in Fig. 10(b)) extending to the depth of $14 \mathrm{~km}$ or more on the DE profile represents Precambrian crystalline rocks of the İstanbul-Zonguldak zone as R2 for the DW profile. Despite the fact that these two resistive zones can be denoted with the same abbreviation according to their same structure, R2 in DW and DE profiles, the magnitude and extension of the $\mathrm{R} 2$ for DE profile is grater than for DW.

As an overall structure in this region, the $2 \mathrm{D}$ electrical resistivity models well represent the structures of the western Pontides. Resistive layers in the northern part represent the İstanbul-Zonguldak zone (Fig. 5), which is the northernmost part of the western Pontides. In the DW model, this resistive layer R2 is sharply cut near the Düzce fault where the low resistive layer starts. This vertical boundary is observed to a depth of $10 \mathrm{~km}$, as seen in Fig. 10(a). Below this depth, the conductive layer dips to the north beneath R2 (DW). Çakır et al. (2003) suggested that the Düzce fault is a vertical fault and that it crosses an old fault dipping to the north. Transition from the resistive layer to the conductive layer near the Düzce fault seems to reflect this structure.

In the DE model, the resistive layer (R2 in Fig. 10(b)), which is an extension of the İstanbul-Zonguldak zone, starts 


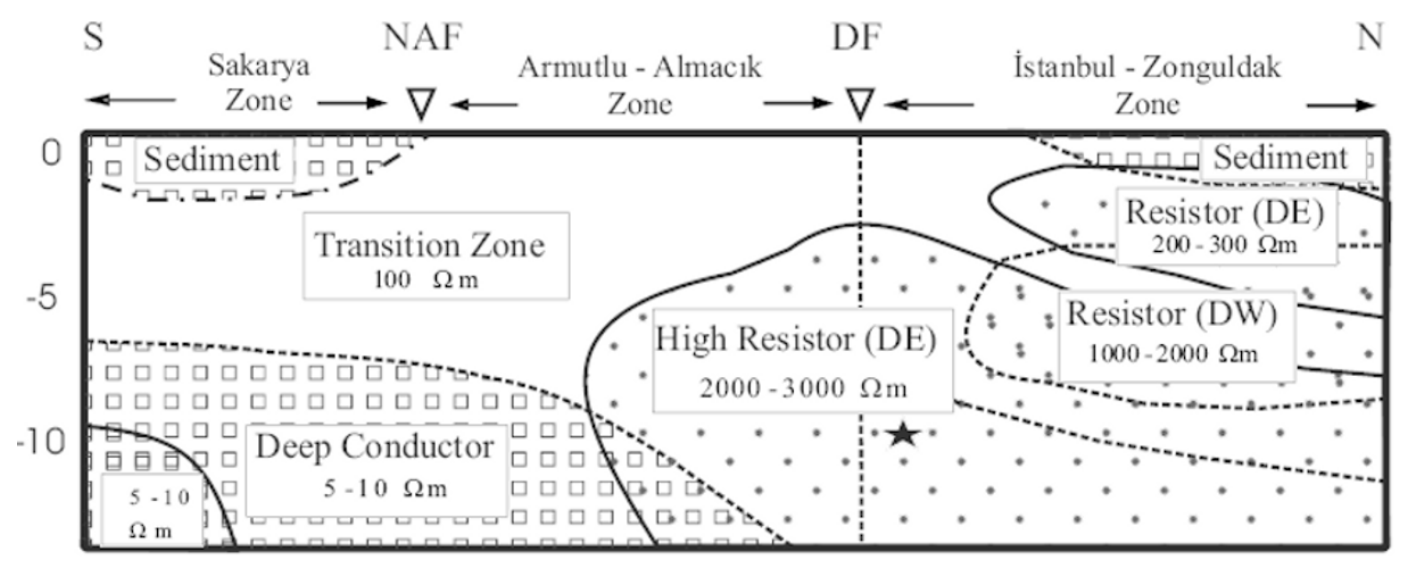

Fig. 11. Electrical resistivity transition beneath the DW and DE profiles. Dashed lines represent structures belonging to the DW profile, solid lines for the DE profile and a chain line represents the structure common for both DW and DE profiles. The star represents the hypocenter of the Düzce earthquake.

at the northern edge of the profile and extends to the north of the NAF where the Armutlu-Almacik zone of the western Pontides ends and the Sakarya continent begins. This layer continues vertically to deep layers, compared with R2 in the DW model. This fundamental difference between two resistive layers may be the reason for the higher rupture velocity observed in the eastern area of the epicenter during the Düzce earthquake.

Birgören et al. (2004) found two asperity zones in the region; a larger one is located near the hypocenter and a small one at shallow depth. These asperity zones are interpreted as indicating high seismic velocity zones, and their locations agree with the high (R2 in Figs. 10(a) and 10(b)) and relatively high (R3 in Fig. 10(b)) resistive layers. Seismicity after the Düzce earthquake is high in the eastern part of the Düzce earthquake epicenter and beneath the DE profile (Fig. 5) where high resistive layers were observed.

The resistivity models of Elmas and Gürer (2004) in eastern İzmit give results similar to that for the DW profile. The MT data used in Elmas and Gürer (2004) were acquired from a profile which crosses the İstanbul-Zonguldak zone, the Armutlu-Almacik zones and the Sakarya continent from the north to the south. Their results show a higher resistivity layer beneath the İstanbul-Zonguldak zone and the Sakarya continent. Between these zones, a similar electrical resistivity transition is seen from the surface to the depth. They showed low resistivity beneath the Sakarya continent and interpreted it as an indication of partial melting or an age difference between the geologic structures of the region. A relatively low resistivity of the Sakarya continent was also shown by Çağlar and İşseven (2004) and interpreted as circulation of hydrothermal fluids.

The 2D resistivity models also correlate well with the MT study of Tank et al. (2005) in the western part of the NAF. These two regions have similar geologic and tectonic structure (Yilmaz et al., 1997). Both of these regions cross western Pontides from the north to the south. Their results indicate that the resistive İstanbul-Zonguldak zone is similar to the 2D electrical resistivity models of the Düzce region. They also explained those resistive zones as asperities and high velocity zones. To the south, there is a transition to the conductive layer in both the model of Tank et al. (2005) and the Düzce models. However, for the Sakarya continent, their results differ from our results. The difference between two models may arise from the fact that their profiles are longer than ours (see Fig. 1(a)). Most probably, our results represent the part of the Sakarya continent near the Armutlu-Almacik zone, but their results include a larger part of this continent.

\section{Conclusions}

MT data were acquired at 23 stations along two parallel profiles on western and eastern sides of the Düzce earthquake epicenter with the aim of imaging electrical resistivity distribution of the region and revealing resistivity contrast between the western and eastern sides.

Following the conventional MT data processing, the geoelectric strikes for the DW and DE profiles were calculated as $\mathrm{N} 72^{\circ} \mathrm{E}$ and $\mathrm{N} 70^{\circ} \mathrm{E}$, respectively. These strike angles are consistent with the geologic strike. The final electrical resistivity models obtained from $2 \mathrm{D}$ inversion agree well with the tectonic and geologic structures in the region. The DW and DE final models well represent the transition of the geologic units and the resistivity distributions of the İstanbulZonguldak zone, the Sakarya continent, and their tectonic mixture Armutlu-Almack zone. In the model for the DW profile, the transition from the resistive to the conductive layer (R2 and C3 in Fig. 10(a)) beneath the Düzce fault at a depth of $\sim 10 \mathrm{~km}$ and the dipping of the conductive layer (C4 in Fig. 10(a)) to the north beneath R2 may be the indicator of the vertical Düzce fault and the north dipping structure as claimed by Çakır et al. (2003). The different electrical resistivity distribution of the DW and DE profiles shown in Fig. 11 clearly represents the dissimilar constitutions of the western and eastern part of the Düzce fault. In this figure, dashed lines represent the structure for the DW profile and solid lines the structures for the DE profile. The high (R2) and relatively low (R3) resistive layers in the DE model (Fig. 10) indicate asperity zones and high seismic velocity zones. The existence of a higher resistive layer on the eastern side (DE profile) of the epicenter and its continuation to the deeper parts (Fig. 11) may be related to both high 
aftershock activities and relatively high rupture velocity on the eastern side.

Acknowledgments. This paper is produced as a result of a joint project between Turkish Scientific and Technical Research Unit (TUBITAK) and National Academy of Sciences of Ukraine with a project number 104Y059 (NASU). We thank Martyn Unsworth from Alberta University for instrumental support. We are grateful to our colleagues who were the hard workers of this project on the field work. We wish to express our deepest gratitude to Yoshimori Honkura and Yasuo Ogawa for their constructive suggestions and critical comments aimed at improving the manuscript. We also would like to thank Makoto Uyeshima, Yasunori Nishida and Malcolm Ingham for their constructive comments which greatly helped improving the manuscript.

\section{References}

Aizawa, K., R. Yoshimura, N. Oshiman, K. Yamazaki, T. Uto, Y. Ogawa, S. B. Tank, W. Kanda, S. Sakanaka, Y. Furukawa, T. Hashimoto, M. Uyeshima, T. Ogawa, I. Shiozaki, and T. Hurst, Hydrothermal system beneath Mt. Fuji volcano inferred from magnetotellurics and electric self-potential, Earth Planet. Sci. Lett., 235, 343-355, 2005.

Akyüz, H. S., R. Hartleb, A. Barka, E. Altunel, G. Sunal, B. Meyer, and ve R. Armijo, Surface rupture and slip distribution of the 12 November 1999 Düzce earthquake ( $M$ 7.1), North Anatolian Fault, Bolu, Turkey, Bull. Seismol. Soc. Am., 92(1), 61-66, 2002.

Ayhan, M. E., R. Bürgman, S. McClusky, O. Lenk, B. Aktug, E. Herece, and R. E. Reilinger, Kinematics of the $M_{\mathrm{W}}=7.2$, 12 November 1999, Düzce, Turkey earthquake, Geophys. Res. Lett., 28, 367-370, 2001.

Berdichevsky, M. N., V. I. Dimitriev, and E. E. Pozdnjakova, On twodimensional interpretation of magnetotelluric soundings, Geophys. $J$. Int., 133, 585-606, 1998

Birgören, G., H. Sekiguchi, and K. Irikura, Rupture model of the 1999 Düzce, Turkey, earthquake deduced from high and low frequency strong motion data, Geophys. Res. Lett., 31, L05610, 2004

Bouin, M. P., M. Bouchon, H. Karabulut, and M. Aktar, Rupture process of the 1999 November 12 Düzce (Turkey) earthquake deduced from strong motion and Global Positioning System measurements, Geophys. J. Int., 159, 207-211, 2004.

Bouchon, M. and H. Karabulut, The aftershock signature of supershear earthquakes, Science, 320, 1323-1325, 2008.

Bouchon, M., M. P. Bouin, H. Karabulut, M. N. Toksöz, M. Dietrich, and A. J. Rosakis, How fast is Rupture during an earthquake? New Insights from the 1999 Turkey earthquakes, Geophys. Res. Lett., 28(14), 27232726, 2001.

Bürgmann, R., M. E. Ayhan, E. J. Fielding, T. J. Wright, S. McClusky, B. Aktug, C. Demir, O. Lenk, and A. Türkezer, Deformation during the 12 November 1999 Düzce, Turkey, earthquake, from GPS and InSar Data, Bull. Seismol. Soc. Am., 92, 161-171, 2002.

Çağlar, I. and T. İşseven, Two-dimensional geoelectrical structure of the Göynük geothermal area, northwest Anatolia, Turkey, J. Volcanol. Geotherm. Res., 134, 183-197, 2004.

Çakır, Z., A. A. Barka, J. B. De Chabalier, R. Armijo, and B. Meyer, Kinematics of the November 12, $1999\left(M_{\mathrm{w}}=7.2\right)$ Düzce earthquake deduced from SAR interferometry, Turkish J. Earth Sci. (Turkish J. Earth Sci.), 12, 105-118, 2003.

Constable, S. C., A. S. Orangez, G. M. Hoversten, and H. F. Morrison, Marine magnetotellurics for petroleum exploration, Part I: A sea-floor equipment system, Geophysics, 63(3), 816-825, 1998.

Elmas, A. and A. Gürer, A comparison of the geological and geoelectrical structures in the Eastern Marmara Region (NW Turkey), J. Asian Earth Sci., 23, 153-162, 2004.

Gamble, T. D., W. M. Goubau, and J. Clark, Magnetotelluric with a remote magnetic reference, Geophysics, 44, 53-68, 1979.

Groom, R. W. and R. C. Bailey, Decomposition of magnetotelluric impedance tensor in the presence of local three-dimensional galvanic distortion, J. Geophys. Res., 94, 1913-1925, 1989.

Gürer, A., Magnetotelluric images of the crust and mantle in the southwestern Taurides, Turkey, Tectonophysics, 392, 109-120, 2004.
Honkura, Y., A. M. Işıkara, N. Oshiman, A. Ito, B. Üçer, Ş. Barış, M. K. Tunçer, M. Matsushima, R. Pektas, C. Çelik, S. B. Tank, F. Takahashi, M. Nakanishi, R. Yoshimura, Y. Ikeda, and T. Komut, Preliminary results of multidisciplinary observations before, during and after the Kocaeli (İzmit) earthquake in the western part of the North Anatolian fault zone, Earth Planets Space, 52, 293-298, 2000.

Jones, A. G., Imaging the continental upper mantle using electromagnetic methods, Lithos, 48, 57-80, 1999.

Key, K. and S. Constable, Broadband Marine MT exploration of the East Pacific Rise at 9 $9^{\circ} 0^{\prime}$ N, Geophys. Res. Lett., 29(22), 2054, 2002.

McNeice, G. W. and A. G. Jones, Multisite, multifrequency tensor decomposition of magnetotelluric data, Geophysics, 66(1), 158-173, 2001.

Ogawa, Y. and T. Uchida, A two-dimensional magnetotelluric inversion assuming Gaussian static shift, Geophys. J. Int., 126, 69-76, 1996.

Ogawa, Y., N. Matsushima, H. Oshima, S. Takakura, M. Utsugi, K. Hirano, M. Igarashi, and T. Doi, A resistivity cross-section of Usu volcano, Hokkaido, Japan, by audiomagnetotelluric soundings, Earth Planets Space, 50, 339-346, 1998.

Oshiman, N., R. Yoshimura, T. Kasaya, Y. Honkura, M. Matsushima S. Baris, C. Celik, M. K. Tunçer, and A. M. Issıkara, Deep resistivity structure around the fault associated with the 1999 Kocaeli earthquake, Turkey, Seismotectonics, in Convergent Plate Boundary, edited by Y. Fujinawa and A. Yoshida, 293-303, Terra Scientific Publishing Company, Tokyo, 2002.

Ritter, O., A. Hoffmann-Rothe, P. A. Bedrosian, U. Weckmann, and V. Haak, Electrical conductivity images of active and fossil fault zones, Geol. Soc. London (Special Publications), 245, 165-186, 2005.

Simpson, F., Intensity and direction of lattice-preferred orientation of olivine: are electrical and seismic anisotropies of the Australian mantle reconcilable?, Earth Planet. Sci. Lett., 203, 535-547, 2002.

Şengör, A. M. C., O. Tüysüz, C. İmren, M. Sakınç, H. Eyidoğan, N. Görür, X. Le Pichon, and C. Rangin, The North Anatolian Fault: A new look, Ann. Rev. Earth Planet. Sci., 33, 37-112, 2005.

Tank, S. B., Y. Honkura, Y. Ogawa, N. Oshiman, M. K. Tunçer, M. Matsushima, C. Çelik, E. Tolak, and A. M. Işıkara, Resistivity structure in the western part of the fault rupture zone associated with the 1999 İzmit earthquake and its seismogenic implication, Earth Planets Space, 55 437-442, 2003.

Tank, S. B., Y. Honkura, Y. Ogawa, M. Matsushima, N. Oshiman, M. K Tunçer, C. Çelik, E. Tolak, and A. M. Işıkara, Magnetotelluric imaging of the fault rupture area of the 1999 İzmit (Turkey) earthquake, Phys. Earth Planet. Inter., 150, 213-225, 2005.

Tibi, R., G. Bock, Y. Xia, M. Baumbach, H. Grosser, C. Milkereit, S. Karakisa, S. Zünbül, R. Kind, and J. Zschau, Rupture process of the 1999 August 17 Izmit and November 12 Düzce (Turkey) earthquakes, Geophys. J. Int., 144, F1-F7, 2001.

Unsworth, M., B. Bedrosian, M. Eisel, G. Egbert, and W. Siripunvaraporn, Along strike variations in the electrical structure of the San Andreas fault at Parkfield, California, Geophys. Res. Lett., 27(18), 3021-3024, 2000 .

Yiğitbaş, E., A. Elmas, and Y. Yılmaz, Pre-Cenozoic tectono-stratigraphic components of the Western Pontides and their geological evolution, Geol. J., 34, 55-74, 1999.

Yılmaz, Y., O. Tüysüz, E. Yiğitbaş, C. Genç, and A. M. C. Şengör, Geology and tectonic evolution of the pontides, in Regional and Petroleum Geology of the Black Sea and surronding region, edited by A. G. Robinson, American Assoc. of. Petrol. Geol., Memoirs 68, 138-226, 1997.

Wannamaker, P. E. and W. M. Doerner, Crustal structure of the Ruby Mountains and southern Carlin Trend region, Nevada, from magnetotelluric data, Ore Geol. Rev., 21, 185-210, 2002.

Wei, W., M. Unsworth, A. Jones, J. Booker, H. Tan, D. Nelson, L. Chen, S. Li, K. Solon, P. Bedrosian, S. Jin, M. Deng, J. Ledo, D. Kay, and B. Roberts, Detection of widespread fluids in the Tibetan Crust by magnetotelluric studies, Science, 292(5517), 716-719, 2001.

T. Kaya (e-mail: tulay.kaya@boun.edu.tr), S. B. Tank, M. K. Tunçer, I. I. Rokoityansky, E. Tolak, and T. Savchenko 